\section{Miniaturised ultra-wideband circularly polarised antenna with modified ground plane}

M. Shokri, V. Rafii, S. Karamzadeh, Z. Amiri and B. Virdee

A unique coplanar-waveguide (CPW)-fed circularly polarised square slot antenna with enhanced impedance bandwidth (IBW) is presented. The antenna structure includes a pair of rectangular-shaped notches located at two opposite corners of the slot for achieving a significantly enhanced IBW of $12.06 \mathrm{GHz}(2.76-14.82 \mathrm{GHz})$, and a pair of reverse L-shaped ground arms in the slot for realising circularly polarised radiation with $1.86 \mathrm{GHz}(4.27-6.13 \mathrm{GHz})$ bandwidth. This proposed technique has the advantages of covering the whole of the ultra-wideband spectrum $(3.1-10.6 \mathrm{GHz})$, an average gain of $3 \mathrm{dBi}$ and a reduced antenna size of $25 \times 25 \times 0.8 \mathrm{~mm}^{3}$

Introduction: The use of circular polarisation (CP) has become a default option in wireless communications systems because of its ability to suppress multipath fading and thus provide significantly enhanced quality of service. Other features that make $\mathrm{CP}$ attractive are its tolerance to adverse weather conditions and elimination of the need for accurate polarisation alignment between antennas [1]. Nowadays wireless systems demand stringent physical requirements from antennas. Various techniques and configurations for CP antennas have been investigated and reported, including the square slot antenna loaded with a cross-patch [2], the square slot antenna fed by an asymmetric coplanar waveguide (CPW) from a corner of the slot [3], the incorporation of a crane-shaped strip in the ground plane [4], applying an open slot [5] and the insertion of inverted-L-shaped ground strips in the slot structure [6]. The relatively large dimensions and limited impedance bandwidth (IBW) characteristics are some of the main deficiencies of the aforementioned CP structures. In this Letter, a novel circularly polarised square slot antenna (CPSSA) configuration is presented that provides a significantly wide IBW of $137.2 \%(2.76-14.82 \mathrm{GHz})$ and an axialratio bandwidth (ARBW) of $35.7 \%$ for $\mathrm{AR} \leq 3 \mathrm{~dB}$ across the wireless local area network (WLAN) band (5.15-5.825 GHz).
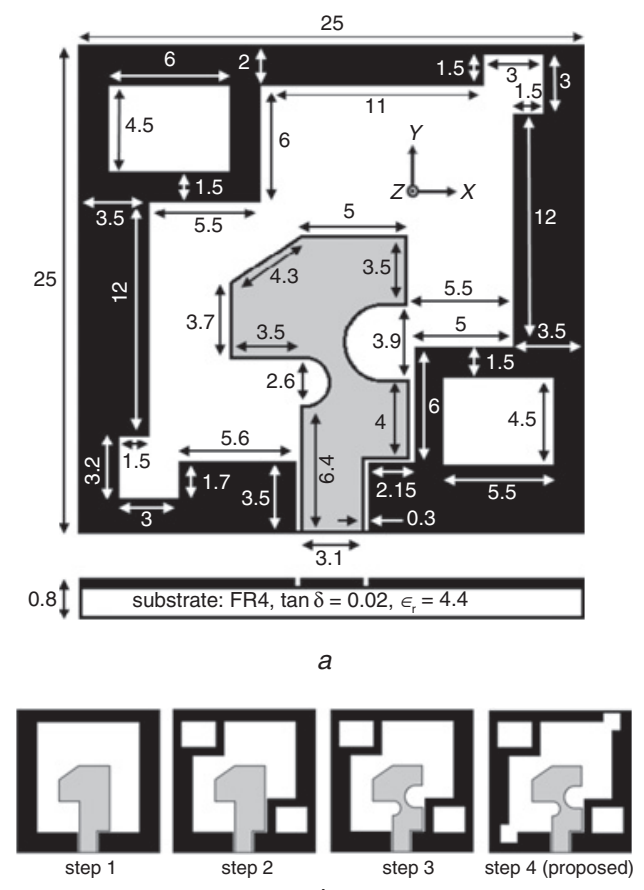

Fig. 1 Steps to realise $C P W$-fed $C P$ slot antenna

$a$ Basic structure of proposed antenna

$b$ Design steps to realise antenna

Antenna design: Fig. $1 a$ shows the geometry of the proposed CPSSA. The antenna consists of a unique radiating patch structure of a quasitrapezoidal shape and is excited by a CPW feed-line that includes two semi-circular notches in the vicinity of the patch. The opposing diagonal corners of the slot are modified with the inclusion of rectangular-shaped notches and reverse L-shaped ground strips. The CPSSA structure was manufactured on FR4 substrate material $\left(\varepsilon_{\mathrm{r}}=4.4\right.$, $\left.\tan \delta=0.02\right)$ of dimensions $25 \times 25 \times 0.8 \mathrm{~mm}^{3}$. The dimensions of the CPW feed-line of 3.1 and $6.4 \mathrm{~mm}$ correspond to a characteristic impedance of $50 \Omega$, and the CPW gap size is $0.3 \mathrm{~mm}$. The patch antenna's impedance was carefully matched to the feed-line by simply extending the feed-line. The dimensions (in millimetres) of the optimised antenna structure are given in Fig. 1a. The stages depicting the evolution of the antenna structure are shown in Fig. $1 b$. Constructed within the rectangular slot are the feed-line and a quasi-trapezoidal-shaped patch; in the second stage, a pair of reverse L-shaped ground strips are inserted in the opposing diagonal corners of the slot; the third stage involves modifying the feedline by cutting semi-circular notches out of it; and finally in the fourth stage, rectangular notches are applied to the other two diagonal corners of the slot.

The $S_{11}$ response and the CP AR of the CPSSA in the four steps are depicted in Fig. 2. Results show that successive steps improve the IBW and AR characteristics of the antenna. Application of ground-plane notches in the fourth step creates additional surface current paths that significantly increase IBW to $12.29 \mathrm{GHz}(2.78-15.07 \mathrm{GHz})$ for $S_{11} \leq$ $-10 \mathrm{~dB}$. The addition of ground-plane notches in the fourth step significantly enhances ARBW between 4.25 and $6.21 \mathrm{GHz}$ for an $\mathrm{AR} \leq 3 \mathrm{~dB}$
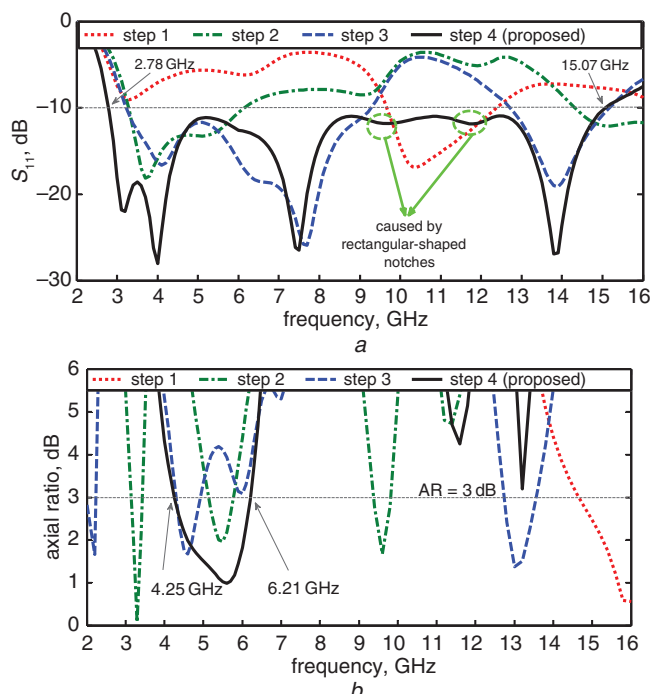

Fig. 2 Return loss $\left(S_{11}\right)$ and AR of antenna in four implementation steps a Return loss response of antenna $b$ AR curves of antenna

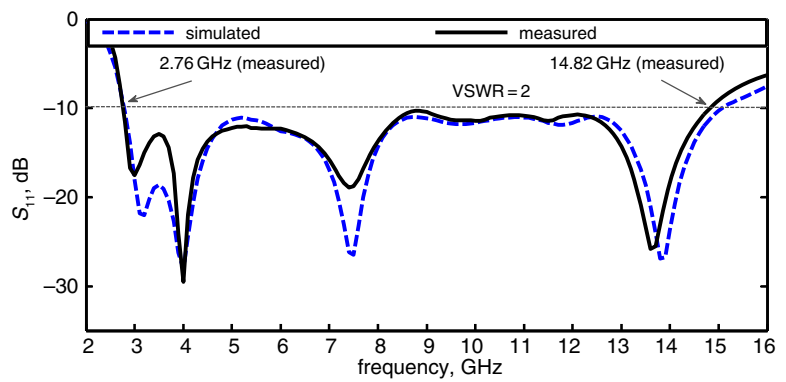

Fig. 3 Measured and simulated return loss of proposed antenna

Antenna performance and analysis: Fig. 3 shows comparison of the simulated (high-frequency structure simulator ver.15) and the measured (Agilent vector network analyser $8722 \mathrm{ES}$ ) return loss performance. The measured IBW is $137.2 \%$ for $S_{11} \leq-10 \mathrm{~dB}$ with the bandwidth ratio $>5.36: 1$. The simulated and measured gains and AR curves, depicted in Fig. 4, are at the direction of maximum radiation $\left(\theta=0^{\circ}\right)$. The measured CP bandwidth is $1.86 \mathrm{GHz}(35.7 \%)$ from 4.27 to $6.13 \mathrm{GHz}$. The average gain measured, shown in Fig. 4 , is almost $3 \mathrm{dBi}$ in the operating band $(3.1-10.6 \mathrm{GHz})$, and the peak gain is about $3.2 \mathrm{dBi}$ at 
10.7 GHz. The results show close correspondence between the measured and simulated curves.

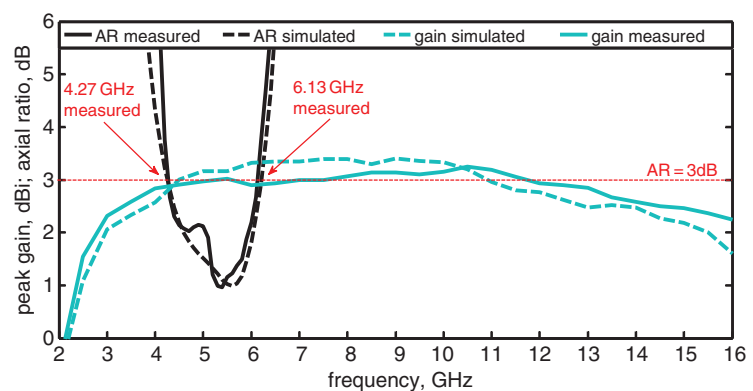

Fig. 4 Antenna's measured and simulated AR and gain

Any discrepancy is attributed to dielectric loss, measurement errors and fabrication tolerance. The current density distribution over the antenna's surface at $5.7 \mathrm{GHz}$, shown in Fig. 5, clearly shows phase reversal of the current vectors at $0^{\circ}$ and $180^{\circ}$, and at $90^{\circ}$ and $270^{\circ}$.

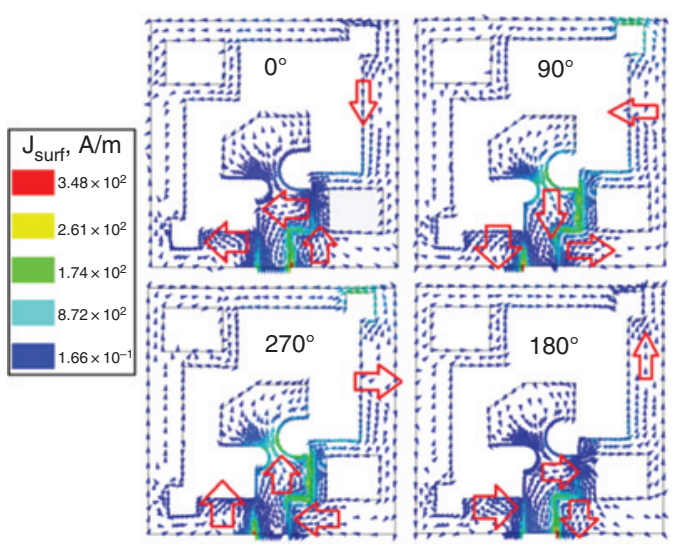

Fig. 5 Surface current density distribution on CPSSA at $5.7 \mathrm{GHz}$ at $0^{\circ}, 90^{\circ}$, $180^{\circ}$ and $270^{\circ}$

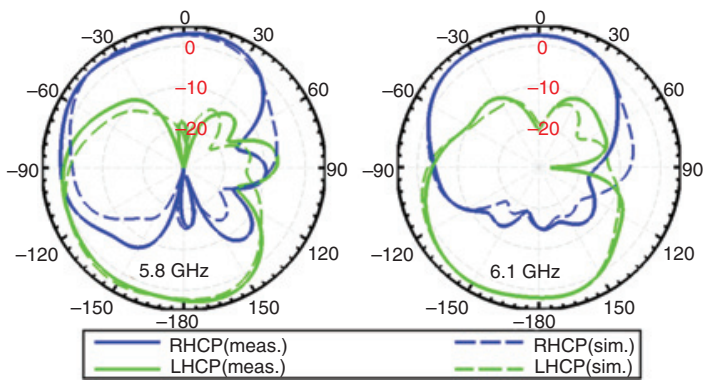

Fig. 6 Measured RHCP and LHCP patterns of proposed CPSSA

Table 1: Comparison of proposed antenna with other works

\begin{tabular}{|c|c|c|c|}
\hline Ref. & IBW & ARBW & Size $\left(\mathrm{mm}^{3}\right)$ \\
\hline$[2]$ & $0.846 \mathrm{GHz}, 39.6 \%$ & $0.24 \mathrm{GHz}, 12.4 \%$ & $\begin{array}{c}70 \times 70 \times \\
1.6\end{array}$ \\
\hline$[3]$ & $0.819 \mathrm{GHz}, 35 \%$ & $0.68 \mathrm{GHz}, 30 \%$ & $\begin{array}{c}60 \times 60 \times \\
0.76\end{array}$ \\
\hline$[4]$ & $0.27 \mathrm{GH}, 17 \%$ and & $0.14 \mathrm{GHz}, 9 \%$ and & $\begin{array}{c}70 \times 70 \times \\
1.6\end{array}$ \\
\hline$[5]$ & $0.43 \mathrm{GHz}, 21 \%$ & $0.22 \mathrm{GHz}, 11 \%$ & $50 \times 50 \times$ \\
& $5.33 \mathrm{GHz}, 111 \%$ & $1 \mathrm{GHz}, 27 \%$ & 0.8 \\
\hline$[6]$ & $8.5 \mathrm{GHz}, 118 \%$ & $1.22 \mathrm{GHz}, 22.2 \%$ & $25 \times 25 \times$ \\
& & & 0.8 \\
\hline This & $12.06 \mathrm{GHz}, 137.2 \%$ & $1.86 \mathrm{GHz}, 35.7 \%$ & $25 \times 25 \times$ \\
work & & & 0.8 \\
\hline
\end{tabular}

The phase reversal of the current over the antenna results in the antenna radiating correspondingly in the RHCP and LHCP. In fact RHCP is generated in the $+z$-direction and LHCP in the $-z$-direction. Fig. 6 shows the measured normalised RHCP and LHCP radiation characteristics of the antenna at 5.8 and $6.1 \mathrm{GHz}$.

Table 1 is arranged in order to compare the performance of the finalised antenna with the previous works reported in [2-6] that are fabricated on the same dielectric substrate for a fair comparison.

Although the size of the proposed antenna is identical to [6], its IBW and ARBW characteristics of 137.2 and $35.7 \%$, respectively, are the best reported to date. The photograph of the fabricated antenna is displayed in Fig. 7.

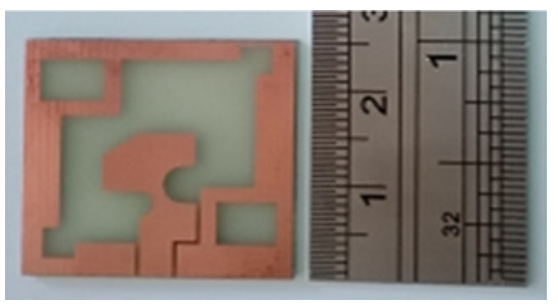

Fig. 7 Photograph of proposed antenna

Conclusion: A miniature CPW-fed CPSSA is proposed with CP operations for ultra-wideband (UWB) and WLAN applications. Results show that the inclusion of rectangular-shaped notches and reverse L-shaped ground arms in the diagonal corners of the ground can significantly enhance the antenna's $3 \mathrm{~dB}$ ARBW and its IBW to 35.7 and $137.2 \%$, respectively. The antenna exhibits a stable average gain of about $3 \mathrm{dBi}$ in its operating band $(3.1-10.6 \mathrm{GHz})$. The antenna has a size of $25 \times 25 \times 0.8 \mathrm{~mm}^{3}$.

(C) The Institution of Engineering and Technology 2014

18 September 2014

doi: $10.1049 / \mathrm{el} .2014 .3278$

One or more of the Figures in this Letter are available in colour online.

M. Shokri, V. Rafii and Z. Amiri (Young Researchers and Elite Club Urmia Branch, Islamic Azad University, Urmia, Iran)

E-mail: majed.shokri@gmail.com

S. Karamzadeh (Department of Electric and Electronics Engineering, Istanbul Aydin University, Istanbul, Turkey)

B. Virdee (Faculty of Life Sciences and Computing, Center for Communications Technology, London Metropolitan University, London, United Kingdom)

\section{References}

1 Ferrero, F., Luxey, C., Jacquemod, G., and Staraj, R.: 'Dual-band circularly polarized microstrip antenna for satellite applications', IEEE Antennas Wirel. Propag. Lett., 2005, 4, pp. 13-15

2 Chou, C.C., Lin, K.H., and Su, H.L.: 'Broadband circularly polarized cross-patch-loaded square slot antenna', Electron. Lett., 2007, 43, (9), pp. $485-486$

3 Sze, J.Y., Wang, J.C., and Chang, C.C.: 'Axial-ratio bandwidth enhancement of asymmetric-CPW-fed circularly-polarized square slot antenna', Electron. Lett., 2008, 44, (18), pp. 1048-1049

4 Chen, C.-H., and Yung, E.K.N.: 'Dual-band circularly-polarized CPW-fed slot antenna with a small frequency ratio and wide bandwidths', IEEE Trans. Antennas Propag., 2011, 59, (4), pp. 1379-1384

5 Jan, J.-Y., Pan, C.-Y., Chiu, K.-Y., and Chen, H.-M.: 'Broadband CPW-fed circularly-polarized slot antenna with an open slot', IEEE Trans. Antennas Propag., 2013, 61, (3), pp. 1418-1422

6 Shirzad, H., Shokri, M., Amiri, Z., Asiaban, S., and Virdee, B.: 'Wideband circularly polarized square slot antenna with an annular patch', Microw. Opt. Technol. Lett., 2014, 56, (1), pp. 229-233 